\title{
Dose-dependent expression of extracellular microRNAs in HCT116 colorectal cancer cells exposed to high-dose-rate ionising radiation
}

\author{
SATORU MONZEN $^{1}$, TATSUYA UENO ${ }^{2}$, MITSURU CHIBA $^{3}$, YUKI MORINO ${ }^{1}$, \\ YASUSHI MARIYA ${ }^{4}$, ANDRZEJ WOJCIK ${ }^{5,6}$ and LOVISA LUNDHOLM ${ }^{5}$
}

\begin{abstract}
${ }^{1}$ Department of Radiation Science, Hirosaki University Graduate School of Health Sciences, Hirosaki, Aomori 036-8564; ${ }^{2}$ Department of Radiology, Southern Tohoku General Hospital, Koriyama, Fukushima 963-8052;

${ }^{3}$ Department of Bioscience and Laboratory Medicine, Hirosaki University Graduate School of Health Sciences, Hirosaki, Aomori 036-8564; ${ }^{4}$ Department of Radiology, Aomori Rosai Hospital, Hachinohe, Aomori 031-8551, Japan;

${ }^{5}$ Department of Molecular Biosciences, The Wenner-Gren Institute, Stockholm University, SE-10691 Stockholm, Sweden; ${ }^{6}$ Institute of Biology, Jan Kochanowski University, 25-369 Kielce, Poland
\end{abstract}

Received September 25, 2020; Accepted October 27, 2021

DOI: $10.3892 / \mathrm{mco} .2021 .2452$

\begin{abstract}
Biomarkers of tumour response to radiotherapy may help optimise cancer treatment. The aim of the present study was to identify changes in extracellular microRNAs (miRNAs) as a biomarker of radiation-induced damage to human colorectal cancer cells. HCT116 cells were exposed to increasing doses of X-rays, and extracellular miRNAs were analysed by microarray. The results were correlated with the frequency of micronuclei. A total of 59 miRNAs with a positive correlation and 4 with a negative correlation between dose (up to $6 \mathrm{~Gy}$ ) and extracellular miRNA expression were identified. In addition, for doses between 0 and $10 \mathrm{~Gy}, 12$ miRNAs among those 59 miRNAs with a positive correlation were identified; for these extracellular miRNAs, a significantly positive correlation was observed between their expression and the frequency of micronuclei for doses up to $10 \mathrm{~Gy}$. These results suggest that specific miRNAs may be considered as cell damage markers and may serve as secreted radiotherapy response biomarkers for colorectal cancer; however, the results must be further validated in serum samples collected from patients undergoing radiotherapy.
\end{abstract}

\section{Introduction}

Colorectal cancer (CRC) is one of the most common types of cancer and the fourth leading cause of cancer-related mortality

Correspondence to: Dr Satoru Monzen, Department of Radiation Science, Hirosaki University Graduate School of Health Sciences, 66-1 Hon-cho, Hirosaki, Aomori 036-8564, Japan

E-mail: monzens@hirosaki-u.ac.jp

Key words: extracellular microRNA, radiotherapy, colorectal cancer, micronuclei worldwide (1). CRC may be associated with pain and compromised quality of life $(2,3)$. Although this type of cancer is mainly treated by surgery, radiotherapy is often used in the neoadjuvant setting to shrink the size of large tumours prior to surgery (4). When surgery is not an option, radiotherapy can be used in combination with chemotherapy as a radical treatment approach (5).

External beam radiotherapy has been used for $>120$ years (6) and is currently considered as a high-precision cancer treatment type that relies on inverse treatment planning and a magnitude of instrumental solutions that allow highly conformal dose delivery (7-10). Despite high dose conformity and intensity, some tumours exhibit a high degree of intrinsic radioresistance, leading to poor therapy outcome (11). Factors responsible for a high intrinsic radioresistance include tumour hypoxia and poor reoxygenation during treatment, repopulation between radiotherapy fractions, efficient repair of DNA damage and a high degree of heterochromatin (11-13).

With respect to $\mathrm{CRC}$, there is considerable interest in devising biomarkers to predict pathological complete response (pCR) of the tumour to a combination of chemoradiotherapy (CRT) and surgery (14). Responsiveness of the tumour to preoperative CRT is crucial, as it may predict clinical outcome and even help decide whether post-CRT surgery is advisable. Han et al (14) analysed several clinical factors to determine their suitability as pCR biomarkers, and found that tumour location and post-CRT levels of the carcinoembryonic antigen (CEA) were promising predictive factors. However, the specificity and sensitivity of these as biomarkers were fairly low (area under the receiver operating characteristic curve comparing sensitivity vs. specificity $=0.638$ ); therefore, additional biomarkers are needed.

Cell response to radiation can be estimated by analysing the release of microRNAs (miRNAs/miRs) to the surrounding medium. miRNAs are small, single-stranded non-coding RNAs that serve an important role in the regulation of gene expression. miRNAs bind to the 3'-untranslated regions of 
target mRNAs and control protein synthesis by increasing mRNA degradation or inhibiting translation (15). miRNAs released extracellularly are contained in extracellular vesicles and circulate in the body (16). miRNA levels and serum composition are promising biomarkers of cancer detection and progression in various types of cancer, including CRC (17-20).

Selected miRNA levels in the serum of patients who underwent radiotherapy for head and neck cancer were found to be correlated with disease remission $(21,22)$. Promising results have also been reported for other types of cancer, including breast or head and neck cancer $(23,24)$.

We became interested in identifying miRNAs that could be used to predict the response of colorectal tumours to radiotherapy. Since miRNAs isolated from the serum of patients undergoing treatment reflect the response of both cancer and normal cells to radiation, it was decided to start the analyses with an in vitro study using a CRC cell line. This approach aims to identify cancer cell-specific changes in the extracellular miRNA content, which, at a later step, can be validated in patient serum. In the present study, the expression of extracellular miRNAs secreted from irradiated HCT116 CRC cells was quantified by microarray and correlated with the frequency of cytogenetic damage. Cells were exposed to single-fraction $\mathrm{X}$-irradiation to assess the basal response of the cell; however, fractionated irradiation is performed in clinical radiotherapy (e.g., 2 Gy/day x 25 fractions). Delivering a small fraction of the total radiation dose allows time for normal cells to repair themselves between treatments, thereby reducing side effects.

\section{Materials and methods}

Cell preparation and culture. The human colorectal cell line HCT116 was purchased from RIKEN BioResource Center. HCT116 cells were maintained in RPMI-1640 medium (Thermo Fisher Scientific, Inc.) supplemented with $10 \%$ heat-inactivated foetal bovine serum (Japan Bioserum, Co., Ltd.) and $1 \%$ penicillin/streptomycin (Thermo Fisher Scientific, Inc.) in a humidified atmosphere at $37^{\circ} \mathrm{C}$ and $5 \%$ $\mathrm{CO}_{2}$.

Irradiation. X-ray irradiation $(150 \mathrm{kVp}, 20 \mathrm{~mA}$ with $0.5-\mathrm{mm}$ aluminium and $0.3-\mathrm{mm}$ copper filters) was performed using an X-ray generator (MBR-1520R-3; Hitachi Medical Co., Ltd.), with a distance of $45 \mathrm{~cm}$ between the focus and target. The dose was monitored with a thimble ionisation chamber placed next to the sample during irradiation. The dose rate was $1 \mathrm{~Gy} / \mathrm{min}$.

Apoptosis assay. The apoptotic cells were examined via direct immunofluorescence flow cytometry (Cell Lab Quanta ${ }^{\mathrm{TM}} \mathrm{Sc}$ MPL; Beckman Coulter Immunotech). Cells harvested using a single pipette were washed twice using Annexin V Binding Buffer (cat. no. 422201) and immunostained following the manufacturer's instructions (BioLegend, Inc.). Following addition of fluorochrome-labelled protein, Annexin V-FITC (cat. no. 640906; BioLegend, Inc.), and propidium iodide (PI; MilliporeSigma), fluorescence intensity was quantified using flow cytometry (Cell Lab QuantaTM Sc MPL) and Kaluza Analysis Software (ver.2.0; Beckman Coulter, Inc.).
Cytokinesis-block micronucleus (CBMN) assay. The $\mathrm{CBMN}$ assay was conducted based of the criteria described by Fenech (25). After exposure of cells to X-irradiation, $15 \mu \mathrm{g} / \mathrm{ml}$ cytochalasin B (Cyt-B; FujiFilm Wako Pure Chemical Corporation) was added to RPMI-1640 medium, and then the cells were harvested after 3 days, which is when the maximum population of binucleated cells (BNCs) could be observed. Harvesting was performed by fixing the cells with $99 \%$ methanol at $-20^{\circ} \mathrm{C}$ for $3 \mathrm{~min}$ and staining with $1 \mu \mathrm{g} / \mathrm{ml}$ Hoechst 33342 (MilliporeSigma) for $30 \mathrm{~min}$ at room temperature. The evaluation was conducted using a fluorescence/ bright-field microscope at x400 magnification (IX71; Olympus Corporation). The BNC fraction was scored per slide for at least $10^{3}$ BNCs. At the same time, the nuclear division index (NDI) was determined from the frequency of $>500$ viable cells (' $\mathrm{N}$ ' indicates the number of viable cells counted per slide) with 1, 2, 3 or 4 nuclei (M1, M2, M3 or M4, respectively) and calculated using the formula, NDI $=[\mathrm{M} 1+(2 \times \mathrm{M} 2)+(3 \times \mathrm{M} 3)$ $+(4 \times \mathrm{M} 4)] / \mathrm{N}$ by fluorescence microscopic observation (25).

RNA extraction. Total extracellular RNAs released from irradiated cells (four replicates performed in parallel) were extracted from the cell culture supernatant using ISOGEN II (Nippon Gene Co., Ltd.), according to the manufacturer's instructions. The collection of RNAs in the cell culture supernatant was performed on day 3 after cell irradiation. This time point was decided as maximum RNA concentration in the cell culture supernatant and maximum percentage of apoptotic cells (26). The concentration of extracted RNAs was examined using Quant-iT RiboGreen RNA Reagent and Kit (Thermo Fisher Scientific, Inc.) and Fluoroskan Ascent (Thermo Fisher Scientific, Inc.). In addition, the peaks of small RNAs were confirmed using Agilent 2100 Bioanalyzer (Agilent Technologies, Inc.). The purity and concentration of extracellular RNAs were assessed using the NanoDrop spectrophotometer (NanoDrop Technologies; Thermo Fisher Scientific, Inc.). The RNA samples had 260/280 nm absorbance ratios of 1.8-2.0.

Microarray analysis. Cy3-labelled miRNA was synthesised from $100 \mathrm{ng}$ total RNA of X-irradiated and non-irradiated cell culture supernatant using miRNA Complete Labelling Reagent and Hyb kit (Agilent Technologies, Inc.). A SurePrint G3 human miRNA microarray slide (8x60 K, Ver. 21.0) was hybridised with the Cy3-labelled miRNA in a hybridisation solution prepared with a Gene Expression Hybridisation kit (Agilent Technologies, Inc.), following the manufacturer's instructions. Cy3 fluorescence signal images on the slide were obtained by using a microarray scanner (Agilent SureScan Microarray Scanner G 2600 D; Agilent Technologies, Inc.) and processed using the Feature Extraction version 10.7 software (Agilent Technologies, Inc.) based on the manufacturer's instructions. In the present study, miRNA samples were collected from cell culture supernatants and the extracellular miRNA content was examined. The expression data were processed using GeneSpring GX14.5 software (Agilent Technologies, Inc.) for normalisation to percentile shift $90 \%$ of all values on the respective microarrays, followed by normalisation of the median expression level of all samples, since using an internal control, such as U6, is not appropriate. 

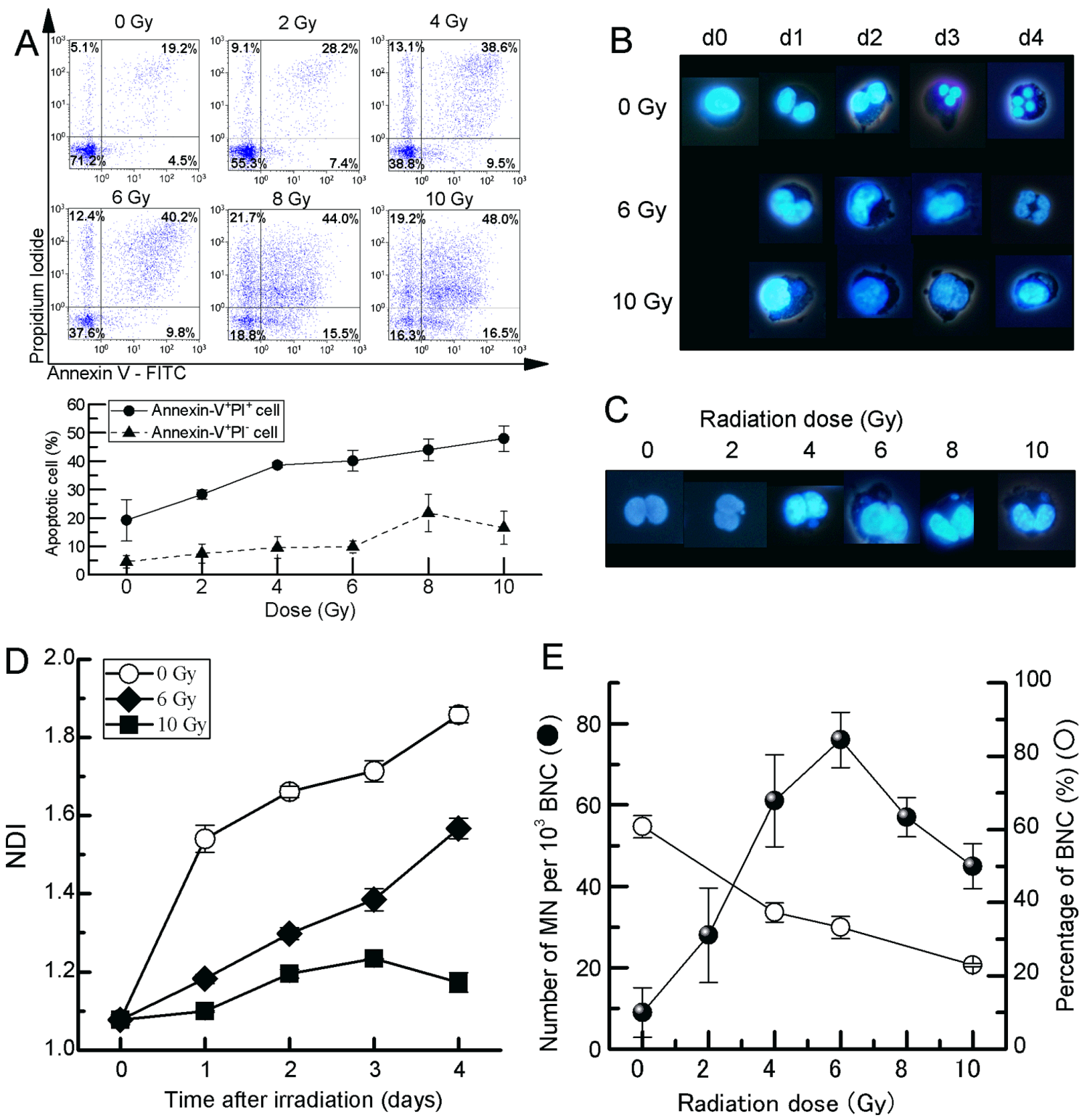

Figure 1. Analysis of CBMN assay in HCT116 cells exposed to X-irradiation. (A) Representative flow cytometry images and percentage of apoptotic cells, (B) representative images of nuclear division after irradiation, (C) BNCs with MN, (D) response of NDI and (E) MN frequency. The cell behaviour in HCT116 cells exposed to 2-10 Gy X-irradiation was observed until day 4. Apoptotic analysis and MN frequency in cells exposed to 2-10 Gy X-irradiation was estimated using flow cytometry (Annexin $\mathrm{V}^{+} / \mathrm{PI}^{-}$early apoptosis and Annexin $\mathrm{V}^{+} / \mathrm{PI}^{+}$late apoptosis) and the CBMN assay, respectively. The cells were cultured with Cyt-B, and $\mathrm{MN}$ and NDI were scored at $72 \mathrm{~h}$ after exposure to X-irradiation. The values are the mean $\pm \mathrm{SE}$ of four separate experiments. CBMN, cytokinesis-block micronucleus; MN, micronuclei; NDI, nuclear division index; BNC, binucleated cell; Cyt-B, cytochalasin B.

The lower raw data signals (lower cut-off of 50) were removed. In addition, the coefficient of variation was also set to $<50.0 \%$ to remove miRNAs with large variations between experiments in advance. The average expression of each miRNA from cells exposed to X-irradiation at 2-10 Gy was compared to control within this normalised dataset (Fig. S1). The results were visualised with the help of heat maps. The microarray low data in the present study were uploaded onto the Gene Expression Omnibus database (GSE184174; https://www.ncbi.nlm.nih. gov/geo/query/acc.cgi?acc=GSE184174).

Statistical analysis. Statistical analysis was performed using OriginLab software version 9.1 (OriginLab) and Excel 2013 (Microsoft Corporation) with the add-in software Statcel 3 (OMS Publishing, Inc.). The significant differences in miRNA expression analysis and cell damage analysis were determined by Pearson's correlation test. $\mathrm{P}<0.05$ was considered to indicate a statistically significant difference.

\section{Results}

Analysis of HCT116 cell damage from X-irradiation. We previously reported that the clonogenic potential of HCT116 cells exposed to high-dose-rate X-irradiation $(1 \mathrm{~Gy} / \mathrm{min})$ is reduced in a dose-dependent manner, and the number of apoptotic cells also increases in a dose-dependent manner (26). The percentage of late apoptotic cells (Annexin $\mathrm{V}^{+} / \mathrm{PI}^{+}$) and early apoptotic cells (Annexin $\mathrm{V}^{+} / \mathrm{PI}^{-}$) by exposure to $2-10 \mathrm{~Gy}$ $\mathrm{X}$-irradiation was found to be $19-50 \%$ and $5-17 \%$, respectively, and it increased in a dose-dependent manner (Fig. 1A). Based 

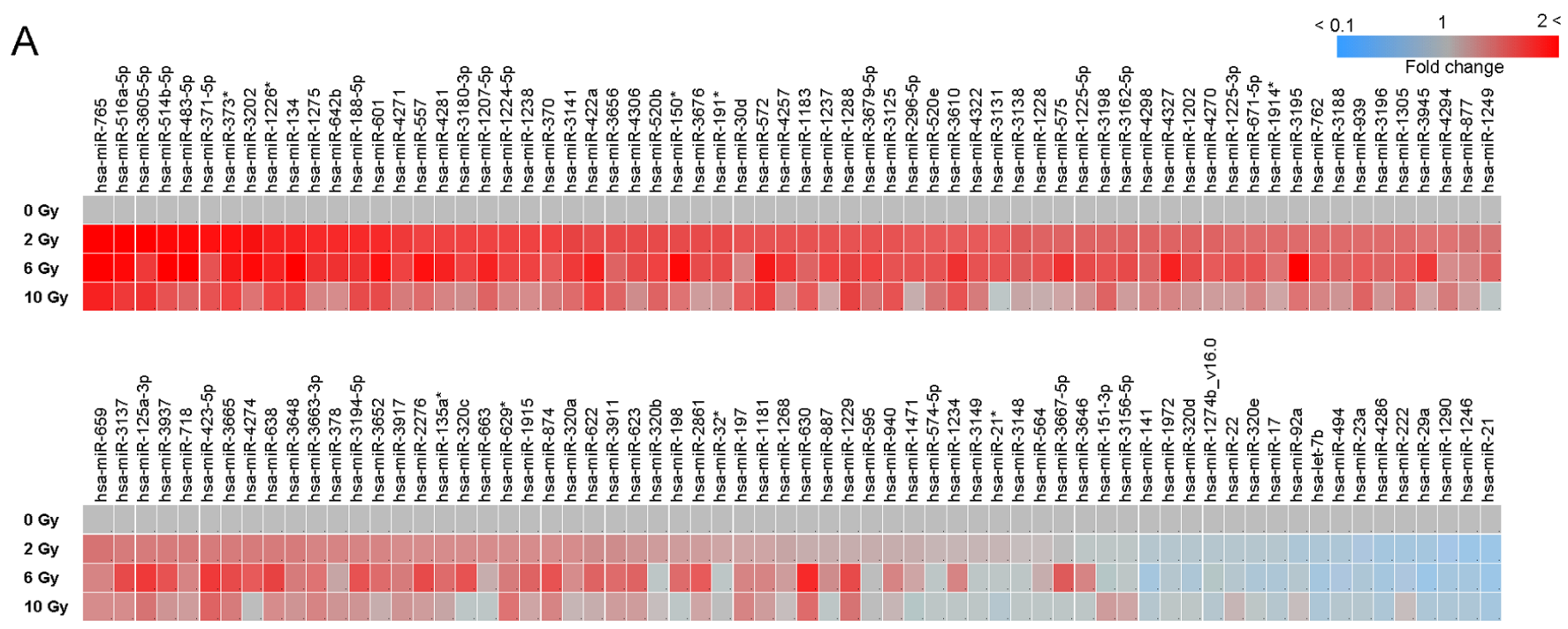

B

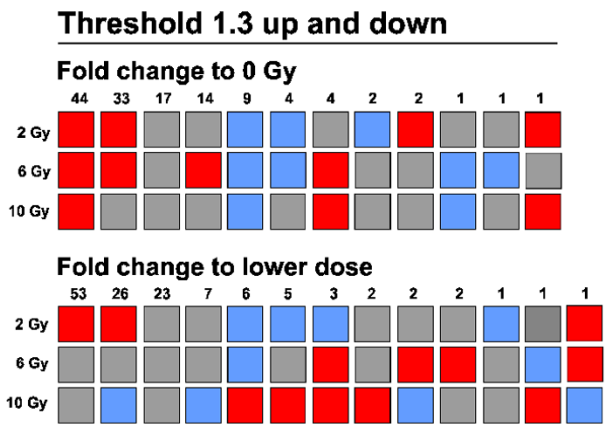

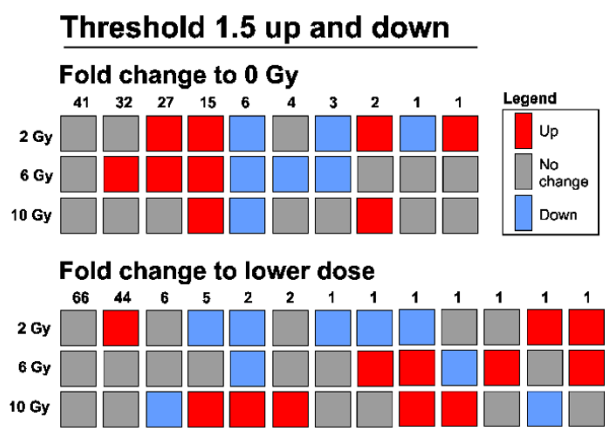

Figure 2. Dataset of miRNAs in focus. (A) Expression of extracellular miRNAs is displayed using a heat map. (B) miRNAs that were up- or downregulated 1.3- or 1.5-fold compared with 0 Gy (left) or the neighbouring lower dose (right) are shown as colour tiles. Upregulation, downregulation and no change are shown as red, blue or grey, respectively. miRNA, microRNA.

on these responses, a CBMN assay was performed using fluorescence microscopy to elucidate whether these cells exhibit dose-dependent nuclear damage by ionising radiation (Fig. 1B and $\mathrm{C}$ ). The NDI, which is a marker of cell proliferation in cultures and is considered as a measure of general cytotoxicity (Fig. 1B), was significantly decreased in HCT116 cells between days 1 and 4 after exposure to 6 and 10 Gy compared with non-irradiated controls (Fig. 1D). As regards the frequency of micronuclei (MN), an increase (76.0 $26.81 \mathrm{MN} / 103 \mathrm{BNCs}$ ) was observed for doses up to $6 \mathrm{~Gy}$; however, a decreased frequency was observed at doses $>6$ Gy (Fig. 1E).

Extracellular miRNA expression following exposure to $X$-irradiation. To determine the miRNAs released from HCT116 cells X-irradiated with 2-10 Gy, the cell culture supernatants were collected, and miRNAs were isolated at day 3 when the maximum ratio of apoptotic cells and $\mathrm{MN}$ frequency were reached $(26,27)$. These samples were applied to $8 \times 60 \mathrm{~K}$ format miRNA microarrays, and 132 human miRbase-annotated miRNAs were detected (Table SI, Fig. 2A). To identify miRNAs responding in a radiation dose-dependent manner, the miRNAs up- and downregulated by 1.3 - or 1.5 -fold were considered, as the number of detectable miRNAs was too small (1 or 0) at an up-/downregulation threshold of 2-fold. Following exposure to 2-10 Gy, 44 and 15 miRNAs were upregulated by 1.3- and 1.5-fold, respectively, vs. the 0 Gy control group. In addition, 9 and 6 miRNAs were downregulated vs. the $0 \mathrm{~Gy}$ control group. On the other hand, no miRNAs were stepwise up- or downregulated by 1.3- and 1.5-fold, respectively, compared with the adjacent lower dose in any of the combinations ( 2 vs. 0,6 vs. 2 or 10 vs. $6 \mathrm{~Gy}$ ). There were still some miRNAs responding in accordance with the 6-Gy peak seen for the MN frequency. When comparing to the adjacent lower dose, patterns of up-up-down/up-up-no change and down-down-up/down-down-no change were found for 1 (miR-3195: 1.3- and 1.5-fold upregulation), 6 (miR-17, miR-29a, miR-98, miR-320d, miR-320e and miR-4286: 1.3-fold downregulation) and 2 (miR-29a and miR-98: 1.5-fold downregulation) miRNAs, respectively. The absolute level of miRNAs may also be a relevant factor allowing for detection in the serum, and miR-572, miR-939 and miR-3610 were the most highly expressed miRNAs on average (Table SI).

To elucidate the statistical correlation between radiation doses and miRNA expression, the 132 miRNA dataset was used, which was created based on the criteria described in Materials and methods. Using samples between 0 and 6 Gy, 59 miRNAs 


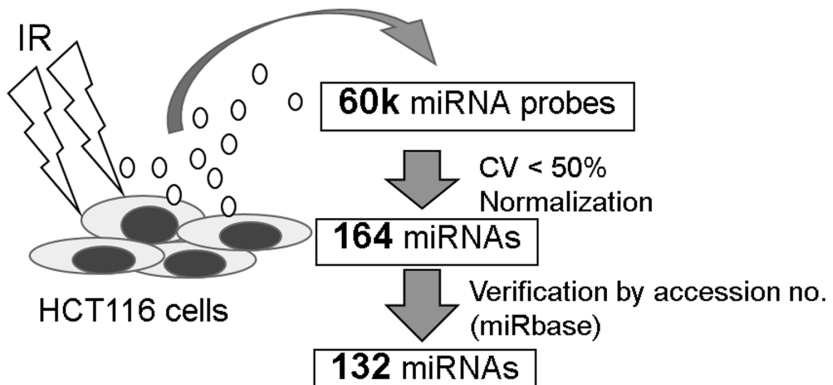

132 miRNAs

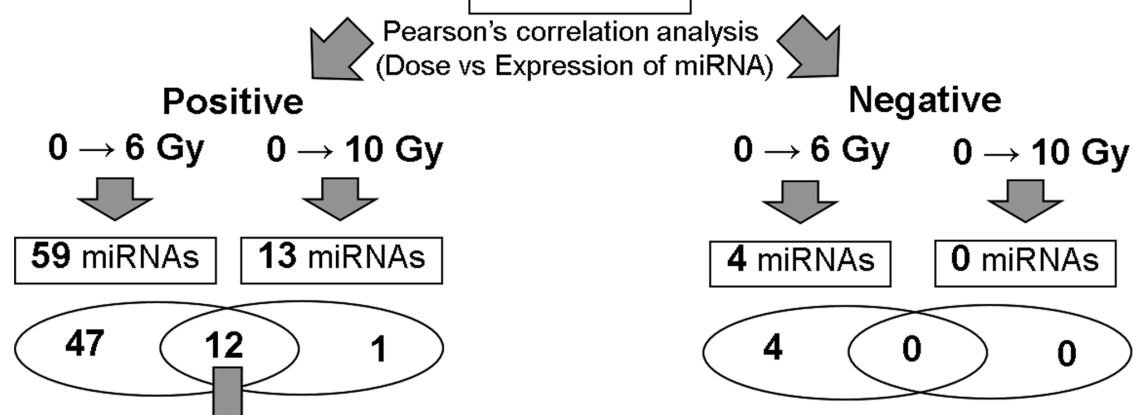

Pearson's correlation analysis

(MN vs Expression of miRNA)

12 miRNAs

Figure 3. Schematic illustration of miRNA analysis. From the miRNA microarray data, initial filtering is displayed. Pearson's correlation analysis was performed between radiation dose and miRNA expression on the 132 filtered miRNAs of focus for this study. The 12 miRNAs exhibiting a significant positive/ negative correlation between MN frequency and miRNA expression were analysed for both the 0-6 Gy and 0-10 Gy ranges. IR, ionizing radiation; miRNA/ miR, microRNA; MN, micronuclei.
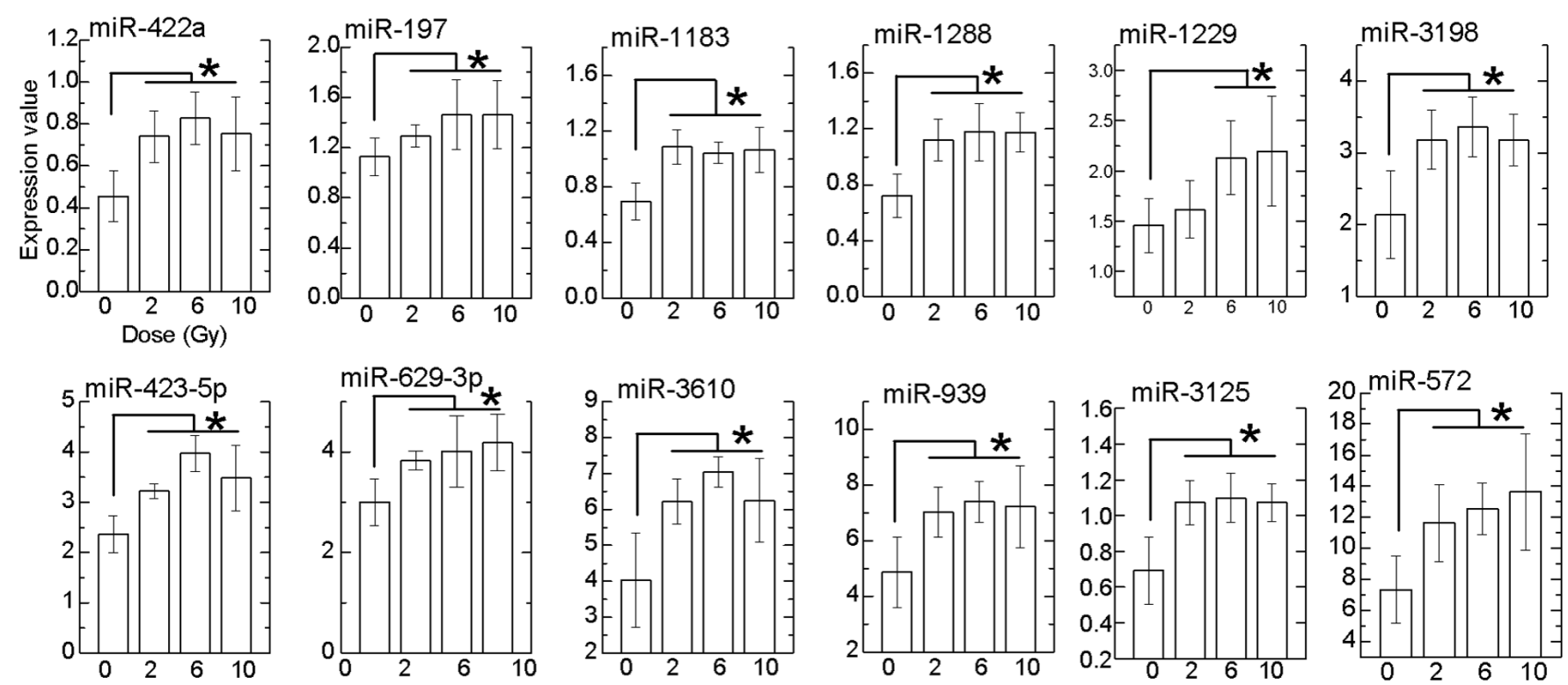

Figure 4. Relationship between radiation dose and miRNA expression. The 16 experimental samples exposed to X-irradiation were analysed, and bar charts of 12 miRNAs in each dose $(0,2,6$ and $10 \mathrm{~Gy})$ are shown. ${ }^{*} \mathrm{P}<0.05$ by Tukey's test. miRNA/miR, microRNA.

exhibiting a positive correlation and 4 miRNAs exhibiting a negative correlation were identified (Fig. 3, Table SII). In addition, for samples between 0 and $10 \mathrm{~Gy}, 13$ miRNAs exhibiting a positive correlation were identified. Of these, 12 miRNAs exhibited significantly upregulated expression at doses between 6 and 10 Gy compared with 0 Gy (Fig. 4). It is known that the maximum limiting dose of MN frequency in blood cells is 3-4 Gy (25). In the present study on HCT 116 cells, the maximum limiting dose was up to 6 Gy (Fig. 1E). To predict the cellular damage and induction of apoptosis by the expression of extracellular miRNAs, we focused on the relationship between the 12 dose-dependently upregulated miRNAs and MN frequency (Fig. 5A), and the percentage of Annexin $\mathrm{V}^{+} / \mathrm{PI}^{+}$cells (Fig. 5B). A significantly positive correlation of all miRNAs (miR-422a, $\mathrm{R}=0.77$; miR-197, $\mathrm{R}=0.50$; miR-1183, $\mathrm{R}=0.63$; $\mathrm{miR}-1288, \mathrm{R}=0.73$; miR-1229, $\mathrm{R}=0.84 ;$ miR-3198, $\mathrm{R}=0.74 ;$ miR-423-5p, $\mathrm{R}=0.78$; 

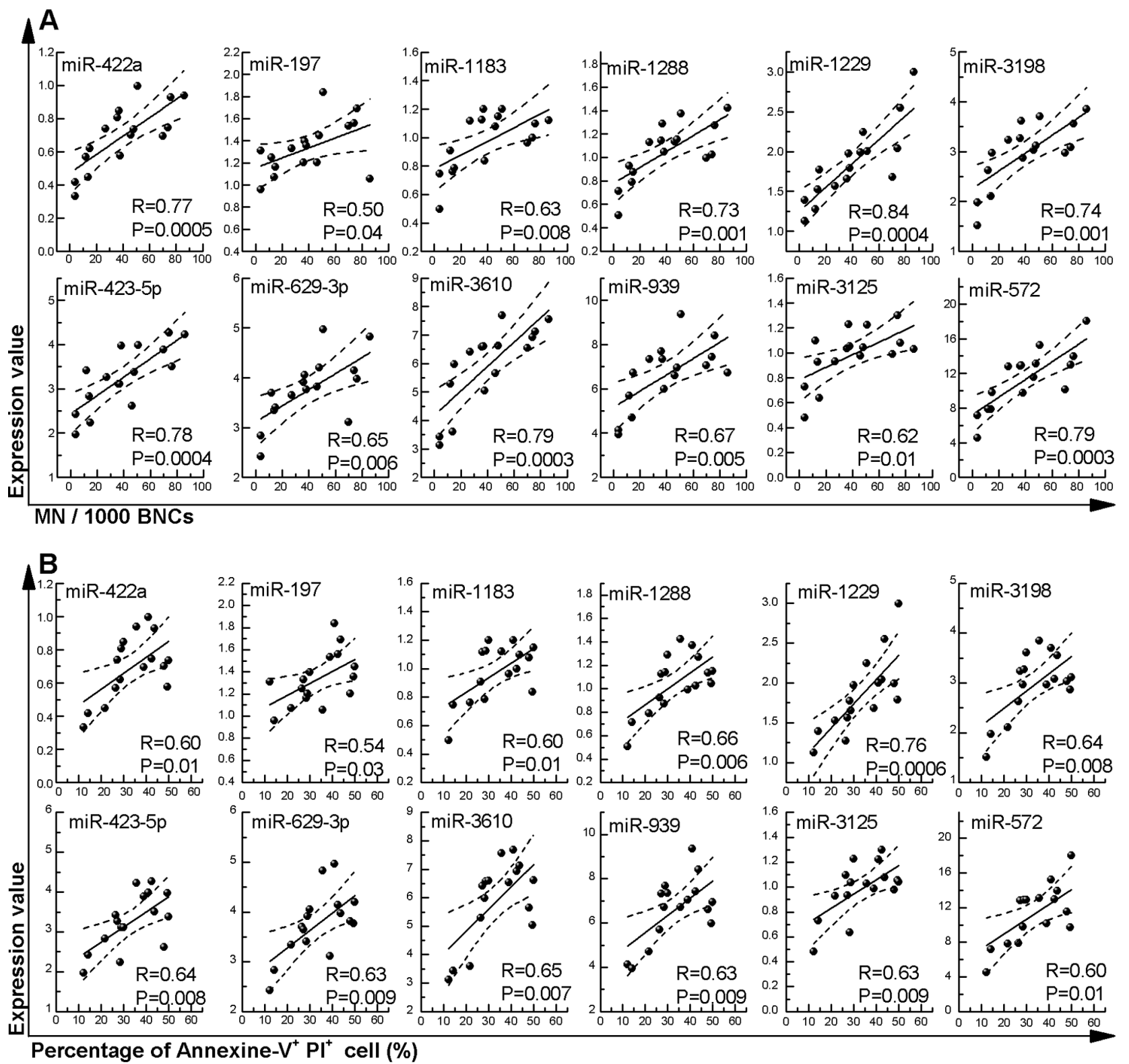

Figure 5. Relationship between (A) MN frequency and miRNA expression and between (B) percentage of Annexin $\mathrm{V}^{+} / \mathrm{PI}^{+}$cells and miRNA expression. The 16 experimental samples exposed to 0-6 Gy X-irradiation were analysed, and cellular MN frequency was correlated with extracellular miRNA expression. The correlation line (black line), 95\% upper confidence limit and lower confidence limit (dotted lines) are shown. R, Pearson's correlation coefficient. MN, micronuclei.

miR-629-3p, R=0.65; miR-3610, R=0.79; miR-939, $\mathrm{R}=0.67$ miR-3125, $\mathrm{R}=0.62$; and miR-572, $\mathrm{R}=0.79$ ) was observed between the expression level and $\mathrm{MN}$ frequency (Fig. 5A). In addition, a significantly positive correlation of all miRNAs (miR-422a, R=0.60; miR-197, $\mathrm{R}=0.54 ;$ miR-1183, $\mathrm{R}=0.60$; miR-1288, R=0.66; miR-1229, $\mathrm{R}=0.76$; miR-3198, $\mathrm{R}=0.76$; miR-423-5p, $\mathrm{R}=0.64$; miR-629-3p, $\mathrm{R}=0.63$; miR-3610, $\mathrm{R}=0.65$; miR-939, $\mathrm{R}=0.63$; miR-3125, $\mathrm{R}=0.63$; and miR-572, $\mathrm{R}=0.60$ ) was also observed with the percentage of Annexin $\mathrm{V}^{+} / \mathrm{PI}^{+}$cells (Fig. 5B).

\section{Discussion}

The aim of the present study was to quantify the expression of extracellular miRNAs released from HCT116 CRC cells exposed to high-dose single-fraction ionising radiation to identify predictive extracellular markers of radiotherapeutic CRC cell damage.

The dose-dependent radiation response at the level of cell nuclear damage, MN (Fig. 1), was in line with the previously reported reduced clonogenic potency for doses up to 6 Gy (26). This increased MN frequency indicates increased number of apoptotic cells. At doses $>6 \mathrm{~Gy}$, increased cell death or cell division arrest most likely contributed to the lower frequency of $\mathrm{MN}$, since a larger proportion of cells with severe damage may have undergone apoptosis at the 72-h time point following exposure to X-irradiation.

In radiation biology, the $\mathrm{CBMN}$ assay is a radiation biodosimetry tool that uses peripheral blood lymphocytes and has an excellent dose dependency (28), contributing to dose estimation within the range of 2-6 Gy in cases of accidental radiation exposure (29). Clinically, $50 \mathrm{~Gy} / 25$ fractions or 
$25 \mathrm{~Gy} / 5$ fractions (30), which corresponds to $2-5$ Gy/fraction, are delivered to the target region for CRC. Therefore, the exposure conditions of the present study are in the clinical range for a single fraction.

It is extremely difficult to analyse the target tissue cells located in deep regions using the CBMN assay in patients undergoing radiotherapy. However, it is possible to use body fluids to detect radiation response markers. A total of 60 specific miRNAs that were released extracellularly and their increased or decreased expression after exposure to $\mathrm{X}$-radiation correlated with dose were identified (Fig. 4). The 12 selected miRNAs included those positively correlated to dose when analysing both 0-6 and 0-10 Gy, which shows that there was a lower expression and MN frequency at $10 \mathrm{~Gy}$ compared with those at $6 \mathrm{~Gy}$. According to the American Society for Radiation Oncology and the Japanese Society for Radiation Oncology $(31,32)$, the clinical fractionation scheme for CRC tissue is delivering $\sim 50 \mathrm{~Gy}$ as a total dose in 25 fractions ( 2 Gy/day). Therefore, miRNA expression in body fluids, such as the serum, has a potential as a monitoring tool within this dose range, whether or not cancer cells are damaged.

In research on biomarkers from body fluids, the peripheral blood, including the metabolites from cancer tissue, has been evaluated for diagnosis and prognosis prediction. In CRC, CEA and carbohydrate antigen 19-9 antigens are considered as representative markers in cancer screening tests (33). Cancer researchers have recently become interested in detailed screening of proteins, DNA and RNA in body fluids for clinical applications to further improve the accuracy of cancer detection (34-37). In recent years, miRNAs have been reported to be highly promising as cancer biomarkers (38). miRNAs regulate various biological processes in cells, and their expression fluctuates with the DNA damage response to radiation (39). Thus, extracellular miRNAs in patients receiving radiotherapy may reflect a radiation-specific response and may be useful for the determination of radiation dose.

Within the data presented herein, it was observed that 8 of 12 miRNAs (miR-422a, miR-197, miR-1183, miR-1288, miR-1229, miR-423-5p, miR-939 and miR-572) have a function in CRC. Intracellular expression of miR-422a, miR-572 and miR-939 serve a role in tumour suppression; miR-422a targets AKT1 and MAPK1; miR-572 targets the MOP-1 pathway activated by STAT3 and miR-939 targets NF- $\kappa \mathrm{B}$ (40-44). Of those, miR-572 and miR-939 were also among the three most highly expressed miRNAs, with the highest chance of detection in the blood. miR-197, miR-1183 and miR-1288 are associated with CRC response (upregulation) to chemotherapy and/or radiotherapy (45-47). miR-423-5p and miR-1229 were reported as diagnostic circulating biomarkers of CRC $(48,49)$. However, the remaining miRNAs (miR-3198, miR-629-3p, miR-3610 and miR-3125) have no previous reports in the field of CRC. Therefore, the phenomenon seen in this study is that the dose-dependent intracellular response to the ionising reaction affected the mRNA release system, including extracellular vesicles. Therefore, these 12 miRNAs may serve as potential biomarkers of radiation response in CRC cells.

Radiotherapy causes activation of several processes in the tumour microenvironment, such as inflammation, cycling hypoxia, immunomodulation, revascularisation, and extracellular matrix remodelling coordinated by cancer-associated fibroblasts and fibrosis (50). The release of miRNAs from tumour cells may contribute to these effects, and it is possible that metabolite control differs among patients with cancer. Of note, there is still a need for improved estimates of which patients are responding well or less well to treatment; therefore, these miRNAs may serve as markers with the purpose of optimising target exposure to the radiation dose during radiotherapy. Further detailed in vitro and in vivo studies are needed to validate these data and to analyse if the expression pattern of these specific miRNAs also contributes to the radiosensitivity of CRC. A limitation of the present study was the lack of investigation of miRNA expression in clinical samples (e.g., colon cancer vs. normal adjacent non-cancerous samples). To verify the evidence on the 12 released extracellular miRNAs, the reproducibility in animal models and/or clinical specimens, and the response of CRC cell exposed to fractionated irradiation, should be further investigated in the future. In addition, we plan to test the role of these 12 miRNAs in endocytosis by CRC cells exposed to high-dose rate ionising radiation.

In conclusion, the findings of the present study suggest that specific extracellular miRNAs have the potential to serve as cell injury markers induced by single high doses of ionising radiation in CRC cells.

\section{Acknowledgements}

Not applicable.

\section{Funding}

The present study was supported by KAKENHI, Grants-in-Aid for Scientific Research, Fund for the Promotion of Joint International Research (Fostering Joint International Research) (project no. 17KK0181) and Grant-in-Aid for challenging Exploratory Research (project no. 19K22731). The funders had no role in study design, data collection and analysis, decision to publish or preparation of the manuscript.

\section{Availability of data and materials}

The datasets used and/or analyzed during the current study are available from the corresponding author on reasonable request.

\section{Authors' contributions}

SM, TU, YMa and LL designed the study, prepared the manuscript draft and substantively participated in revising the manuscript. SM, TU, YMo and MC contributed by analysing the biological data. TU and AW contributed by normalizing by the microarray data. All authors read and approved the final manuscript.

\section{Ethics approval and consent to participate}

Not applicable.

\section{Patient consent for publication}

Not applicable. 


\section{Competing interests}

The authors declare that they have no competing interests.

\section{References}

1. Araghi M, Soerjomataram I, Jenkins M, Brierley J, Morris E, Bray F and Arnold M: Global trends in colorectal cancer mortality: Projections to the year 2035. Int J Cancer 144 2992-3000, 2019.

2. Siegel RL, Miller KD and Jemal A: Cancer statistics, 2019. CA Cancer J Clin 69: 7-34, 2019.

3. Arnold M, Sierra MS, Laversanne M, Soerjomataram I, Jemal A and Bray F: Global patterns and trends in colorectal cancer incidence and mortality. Gut 66: 683-691, 2017.

4. van Gijn W, Marijnen CA, Nagtegaal ID, Kranenbarg EM, Putter H, Wiggers T, Rutten HJ, Påhlman L, Glimelius B and van de Velde CJ; Dutch Colorectal Cancer Group: Preoperative radiotherapy combined with total mesorectal excision for resectable rectal cancer: 12-year follow-up of the multicentre, randomised controlled TME trial. Lancet Oncol 12: 575-582, 2011.

5. Kye $\mathrm{BH}$ and Cho HM: Overview of radiation therapy for treating rectal cancer. Ann Coloproctol 30: 165-174, 2014.

6. No authors listed: News of Science. Science 125: 18-22, 1957.

7. Brock KK, McShan DL, Ten Haken RK, Hollister SJ, Dawson LA and Balter JM: Inclusion of organ deformation in dose calculations. Med Phys 30: 290-295, 2003.

8. De Ruysscher D, Belderbos J, Reymen B, van Elmpt W, van Baardwijk A, Wanders R, Hoebers F, Vooijs M, Ollers M and Lambin P: State of the art radiation therapy for lung cancer 2012: A glimpse of the future. Clin Lung Cancer 14: 89-95, 2013.

9. Emami B, Lyman J, Brown A, Coia L, Goitein M, Munzenrider JE, Shank B, Solin LJ and Wesson M: Tolerance of normal tissue to therapeutic irradiation. Int J Radiat Oncol Biol Phys 21: 109-122, 1991.

10. Marks LB, Yorke ED, Jackson A, Ten Haken RK, Constine LS, Eisbruch A, Bentzen SM, Nam J and Deasy JO: Use of normal tissue complication probability models in the clinic. Int J Radiat Oncol Biol Phys 76 (Suppl): S10-S19, 2010.

11. Baumann M, Krause M, Overgaard J, Debus J, Bentzen SM, Daartz J, Richter C, Zips D and Bortfeld T: Radiation oncology in the era of precision medicine. Nat Rev Cancer 16: 234-249, 2016.

12. Tang L, Wei F, Wu Y, He Y, Shi L, Xiong F, Gong Z, Guo C, Li X, Deng $\mathrm{H}$, et al: Role of metabolism in cancer cell radioresistance and radiosensitization methods. J Exp Clin Cancer Res 37: 87, 2018.

13. Chen T, Zhang Y, Guo WH, Meng MB, Mo XM and Lu Y: Effects of heterochromatin in colorectal cancer stem cells on radiosensitivity. Chin J Cancer 29: 270-276, 2010.

14. Han YD, Kim WR, Park SW, Cho MS, Hur H, Min BS, Baik SH Lee KY and Kim NK: Predictors of pathologic complete response in rectal cancer patients undergoing total mesorectal excision after preoperative chemoradiation. Medicine (Baltimore) 94 e1971, 2015.

15. Valadi H, Ekström K, Bossios A, Sjöstrand M, Lee JJ and Lötvall JO: Exosome-mediated transfer of mRNAs and microRNAs is a novel mechanism of genetic exchange between cells. Nat Cell Biol 9: 654-659, 2007.

16. Czochor JR and Glazer PM: microRNAs in cancer cell response to ionizing radiation. Antioxid Redox Signal 21: 293-312, 2014

17. Mitchell PS, Parkin RK, Kroh EM, Fritz BR, Wyman SK, Pogosova-Agadjanyan EL, Peterson A, Noteboom J, O'Briant KC Allen A, et al: Circulating microRNAs as stable blood-based markers for cancer detection. Proc Natl Acad Sci USA 105: 10513-10518, 2008.

18. Bhat SA, Majid S and Hassan T: MicroRNAs and its emerging role as breast cancer diagnostic marker - A review. Adv Biomarke Sci Technol 1: 1-8, 2019.

19. Yu H, Guan Z, Cuk K, Zhang Y and Brenner H: Circulating microRNA biomarkers for lung cancer detection in East Asian populations. Cancers (Basel) 11: 415, 2019.

20. Masuda T, Hayashi N, Kuroda Y, Ito S, Eguchi H and Mimori K MicroRNAs as biomarkers in colorectal cancer. Cancers (Basel) 9: 124, 2017.
21. Chen L, Wen Y, Zhang J, Sun W, Lui VWY, Wei Y, Chen F and Wen W: Prediction of radiotherapy response with a 5-microRNA signature-based nomogram in head and neck squamous cell carcinoma. Cancer Med 7: 726-735, 2018.

22. Pasi F, Corbella F, Baio A, Capelli E, De Silvestri A, Tinelli C and Nano R: Radiation-induced circulating miRNA expression in blood of head and neck cancer patients. Radiat Environ Biophys 59: 237-244, 2020.

23. Halimi M, Parsian H, Mohsen Asghari S, Sariri R, Moslemi D and Yeganeh F: MicroRNAs: Are they indicators for prediction of response to radiotherapy in breast cancer? Irn J Med Hypotheses Ideas 7: 59-64, 2013

24. Moertl S, Mutschelknaus L, Heider T and Atkinson MJ: MicroRNAs as novel elements in personalized radiotherapy. Transl Cancer Res 5: S1262-S1269, 2016.

25. Fenech M: Cytokinesis-block micronucleus cytome assay. Nat Protoc 2: 1084-1104, 2007.

26. Ueno T, Monzen S, Chiba M, Morino $Y$ and Hosokawa $Y$ : Screening for biological marker of dose-optimization in cancer radiotherapy. Nippon Hoshasen Gijutsu Gakkai Zasshi 74 459-464, 2018 (In Japanese).

27. Ueno T, Monzen S, Chiba M and Hosokawa Y: Basic investigation to optimize radiation dose using biological evaluation in radiotherapy. Cytometry Res 28: 7-11, 2018.

28. International Atomic Energy Agency: Cytogenetic Dosimetry: Applications in Preparedness for and Response to Radiation Emergencies. EPR-Biodosimetry 2011. Vienna, 2011.

29. Liu Q, Cao J, Wang ZQ, Bai YS, Lü YM, Huang QL, Zhao WZ, Li J, Jiang LP, Tang WS, et al: Dose estimation by chromosome aberration analysis and micronucleus assays in victims accidentally exposed to (60)Co radiation. Br J Radiol 82: 1027-1032, 2009.

30. Rodrigues G, Velker V and Best L: Radiation Oncology Primer and Review, Essential Concepts and Protocols. 1st edition. Demos MEDICAL, pp1-376, 2013.

31. Japanese Society for Radiation Oncology: JASTRO Guidelines 2020 for Radiotherapy Treatment Planning. Fifth edition. Kanehara \& Co. Ltd., 2020. (In Japanese)

32. Wo JY, Anker CJ, Ashman JB, Bhadkamkar NA, Bradfield L, Chang DT, Dorth J, Garcia-Aguilar J, Goff D, Jacqmin D, et al: Radiation therapy for rectal cancer: Executive summary of an ASTRO clinical practice guideline. Pract Radiat Oncol 11: 13-25, 2021.

33. Lech G, Słotwiński R, Słodkowski M and Krasnodebski IW: Colorectal cancer tumour markers and biomarkers: Recent therapeutic advances. World J Gastroenterol 22: 1745-1755, 2016.

34. Babel I, Barderas R, Díaz-Uriarte R, Martínez-Torrecuadrada JL, Sánchez-Carbayo M and Casal JI: Identification of tumor-associated autoantigens for the diagnosis of colorectal cancer in serum using high density protein microarrays. Mol Cell Proteomics 8: 2382-2395, 2009

35. Oh T, Kim N, Moon Y, Kim MS, Hoehn BD, Park CH, Kim TS Kim NK, Chung HC and An S: Genome-wide identification and validation of a novel methylation biomarker, SDC2, for blood-based detection of colorectal cancer. J Mol Diagn 15: 498-507, 2013

36. Han M, Liew CT, Zhang HW, Chao S, Zheng R, Yip KT, Song ZY, Li HM, Geng XP, Zhu LX, et al: Novel blood-based, five-gene biomarker set for the detection of colorectal cancer. Clin Cancer Res 14: 455-460, 2008.

37. Wang S, Xiang J, Li Z, Lu S, Hu J, Gao X, Yu L, Wang L, Wang J, Wu Y, et al: A plasma microRNA panel for early detection of colorectal cancer. Int J Cancer 136: 152-161, 2015.

38. Chen X, Ba Y, Ma L, Cai X, Yin Y, Wang K, Guo J, Zhang Y, Chen J, Guo X, et al: Characterization of microRNAs in serum: A novel class of biomarkers for diagnosis of cancer and other diseases. Cell Res 18: 997-1006, 2008 .

39. Bartel DP: MicroRNAs: Genomics, biogenesis, mechanism, and function. Cell 116: 281-297, 2004.

40. Faltejskova P, Svoboda M, Srutova K, Mlcochova J, Besse A, Nekvindova J, Radova L, Fabian P, Slaba K, Kiss I, et al: Identification and functional screening of microRNAs highly deregulated in colorectal cancer. J Cell Mol Med 16: 2655-2666, 2012.

41. Wei WT, Nian XX, Wang SY, Jiao HL, Wang YX, Xiao ZY, Yang RW, Ding YQ, Ye YP and Liao WT: miR-422a inhibits cell proliferation in colorectal cancer by targeting AKT1 and MAPK1. Cancer Cell Int 17: 91, 2017.

42. Cui C, Yu J, Huang S, Zhu H and Huang Z: Transcriptional regulation of gene expression by microRNAs as endogenous decoys of transcription factors. Cell Physiol Biochem 33: 1698-1714, 2014. 
43. Cui C, Zhai D, Cai L, Duan Q, Xie L and Yu J: Long noncoding RNA HEIH promotes colorectal cancer tumorigenesis via counteracting miR-939-mediated transcriptional repression of Bcl-xL. Cancer Res Treat 50: 992-1008, 2018.

44. Wang N, He X, Zhou R, Jia G and Qiao Q: STAT3 induces colorectal carcinoma progression through a novel miR-572-MOAP-1 pathway. OncoTargets Ther 11: 3475-3484, 2018.

45. Wang M, Hu H, Wang Y, Huang Q, Huang R, Chen Y, Ma T, Qiao T, Zhang Q, Wu H, et al: Long non-coding RNA TUG1 mediates 5-fluorouracil resistance by acting as a ceRNA of miR-197-3p in colorectal cancer. J Cancer 10: 4603-4613, 2019.

46. Della Vittoria Scarpati G, Falcetta F, Carlomagno C, Ubezio P, Marchini S, De Stefano A, Singh VK, D'Incalci M, De Placido S and Pepe S: A specific miRNA signature correlates with complete pathological response to neoadjuvant chemoradiotherapy in locally advanced rectal cancer. Int J Radiat Oncol Biol Phys 83: $1113-1119,2012$
47. Gopalan V, Pillai S, Ebrahimi F, Salajegheh A, Lam TC, Le TK, Langsford N, Ho YH, Smith RA and Lam AK: Regulation of microRNA-1288 in colorectal cancer: Altered expression and its clinicopathological significance. Mol Carcinog 53 (Suppl 1): E36-E44, 2014.

48. $\mathrm{Lu} \mathrm{X}$ and $\mathrm{Lu} \mathrm{J}$ : The significance of detection of serum miR-423-5p and miR-484 for diagnosis of colorectal cancer. Clin Lab 61: 187-190, 2015

49. Ogata-Kawata H, Izumiya M, Kurioka D, Honma Y, Yamada Y, Furuta K, Gunji T, Ohta H, Okamoto H, Sonoda H, et al: Circulating exosomal microRNAs as biomarkers of colon cancer. PLOS ONE 9: e92921, 2014.

50. Barker HE, Paget JT, Khan AA and Harrington KJ: The tumour microenvironment after radiotherapy: mechanisms of resistance and recurrence. Nat Rev Cancer 15: 409-425, 2015. 